\title{
Spectral and Electrochemical Studies on Blends of Polyaniline and Cellulose Esters
}

\author{
A. P. Marques, ${ }^{1}$ C. M. A. Brett ${ }^{1}$ H. D. Burrows, ${ }^{1}$ A. P. Monkman, ${ }^{2}$ B. Retimal $^{2}$ \\ ${ }^{1}$ Departamento de Química, Universidade de Coimbra, 3004-535 Coimbra, Portugal \\ ${ }^{2}$ Organic Electroactive Materials Research Group, Department of Physics, University of Durham, \\ DH1 3LE, United Kingdom
}

Received 6 April 2001; accepted 13 February 2002

\begin{abstract}
Blends of chemically prepared polyaniline emeraldine base (PANi) with cellulose esters were studied as films by UV-visible spectroscopy and cyclic voltammetry. The cellulose esters used were acetate, propionate, acetate butyrate, and acetate hydrogen phthalate. Films were prepared by casting from $N$-methylpyrrolidone or formic acid, and the effect of doping by acids on their spectral and electrochemical properties was studied. Similar behavior was observed with the acetate, propionate, or acetate butyrate, with spectral changes on adding acid due to protonation of the PANi. In agreement with previous studies, kinetic measurements on PANi in a cellulose acetate matrix shows a relatively slow spectral change on protonation. In contrast, with cellulose acetate hydrogen phthalate (CAHP),
\end{abstract}

no changes were observed on adding acid, and it is suggested that the hydrogen phthalate group acts as proton donor. This was mirrored by the cyclic voltammetry behavior in hydrochloric acid solution. Electrochemical studies on films of PANi/CAHP blends in different relative proportions in sulfuric acid solution show a marked dependence on the solvent used for casting, with higher currents and better electrical conductivity being observed in films prepared from $N$-methylpyrrolidone. This is shown to be due to the presence of PANi particles in the films. (C) 2002 Wiley Periodicals, Inc. J Appl Polym Sci 86: 2182-2188, 2002

Key words: conducting polymers; electrochemistry; films; spectroscopy

\section{INTRODUCTION}

Conjugated organic polymers now constitute a major area of research and development, with actual and potential applications in many fields of molecular electronics, such as electrical contacts and shielding, molecular sensors, and light emitting diodes. ${ }^{1-6}$ Because of its low cost, stability, chemical purity, and processibility, polyaniline (PANi) is one of the most attractive conductive polymers for commercial applications $^{7-9}$ in areas as diverse as rechargeable batteries, ${ }^{10}$ electrochromic systems, ${ }^{11,12}$ electrocatalysis, ${ }^{13,14}$ sensors, ${ }^{15,16}$ anticorrosion agents, ${ }^{17,18}$ separation science, ${ }^{19}$ hole-injection layers in light emitting diodes, ${ }^{20}$ antistatic coatings, ${ }^{21}$ and in electromagnetic shielding. ${ }^{22} \mathrm{~A}$ major advance in its applications came with the discovery that the electrically conducting emeraldine form doped with sulfonic acids could be processed from solution, ${ }^{23}$ and this has been followed by the development of highly conducting wet-spun fibers

Correspondence to: C. M. A. Brett (brett@ci.uc.pt).

Contract grant sponsor: British Council/CRUP; contract grant number: B-9/97; contract grant sponsor: PRAXIS XXI; contract grant number: 2/2.1/411/94; contract grant sponsor: EPSRC; contract grant number: GR/M 40387.

Journal of Applied Polymer Science, Vol. 86, 2182-2188 (2002) (c) 2002 Wiley Periodicals, Inc. of PANi with a polymeric sulfonic acid, with conductivities up to $1950 \mathrm{~S} \mathrm{~cm}^{-1}{ }^{24}$

However, the application of the excellent electrical and optical characteristics of PANi is frequently limited by its poor mechanical properties. There is active interest in the development of appropriate blends with insulating polymers which can be processed from solution, and which will combine good electronic and mechanical properties. Among the insulating polymers which have been studied for these applications are poly(methyl methacrylate) ${ }^{25,26}$ polyesters ${ }^{25,26}$ poly(vinyl alcohol) ${ }^{27}$ poly(vinyl chloride) ${ }^{28}$ and polycarbonates. ${ }^{29}$ The very good film-forming capabilities of cellulose derivatives would seem to make them excellent candidates as matrices for PANi for such applications, and a number of studies were reported on blends of PANi with the ester cellulose acetate ${ }^{30-35}$ However, both the film quality and the hydrophobicity of cellulose esters depend markedly on the derivative used and the processing conditions. ${ }^{36}$ We have, therefore, made a study of the electrochemical and spectral properties of blends of PANi with various cellulose esters. PANi as a free base exists in three main forms, leucoemeraldine, emeraldine, and pernigraniline. ${ }^{37}$ This study used the half-oxidized emeraldine base form (Fig. 1), which was chemically prepared in a high state of purity. ${ }^{38}$ Films were prepared by casting from solutions in $\mathrm{N}$-methylpyrro- 


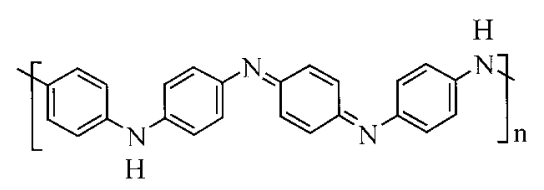

Figure 1 Structure of emeraldine base form of polyaniline.

lidone or formic acid. A particularly promising host polymer was cellulose acetate hydrogen phthalate, which was shown to be capable of partially protonating the PANi.

\section{EXPERIMENTAL}

\section{Materials}

The cellulose esters cellulose acetate (CA), cellulose propionate $(\mathrm{CP})$, cellulose acetate butyrate $(\mathrm{CAB})$, and cellulose acetate hydrogen phthalate (CAHP) were all obtained from Aldrich (Madrid) and used without further treatment. Three different cellulose acetate samples were used, polydisperse with 53.5-54.5\% acetylation, and two relatively monodisperse samples with $39.7-39.8 \%$ acetylation and molecular weights of 30,000 and 50,000. High-purity polyaniline, in powder form, was prepared by chemical polymerization. ${ }^{38}$ The solvents $N$-methylpyrrolidone (NMP), formic acid, and other reagents were all of analytical grade and were used without further treatment.

\section{Film preparation}

In initial experiments, relatively thick films (10-40 $\mu \mathrm{m})$ were prepared by solvent casting from solutions of mixtures of PANi and the appropriate cellulose ester in NMP. The cellulose derivative and PANi were dissolved separately in the solvent with moderate heating, and then the solutions were mixed. In some cases, the mixtures were filtered. For spectroscopic studies, films were cast onto glass microscope slides, whereas for electrochemical measurements, they were prepared on glassy carbon electrodes. Solvents were evaporated in a vacuum oven at $40^{\circ} \mathrm{C}$. Sample homogeneity of the films was studied by optical observation by using Nikon Optiphotol, M35S, or Leica DMR microscopes in transmission mode. In addition, for films on glassy carbon electrodes, observations were also made in reflectance mode.

Subsequent studies concentrated on blends of PANi with cellulose acetate hydrogen phthalate (CAHP). For these, a chosen mass $(17,34$, or $65 \mathrm{mg})$ of PANi was dissolved in $2.5 \mathrm{~cm}^{3}$ of the solvent NMP or formic acid and mixed with a solution of $17 \mathrm{mg}$ CAHP in 2.5 $\mathrm{cm}^{3}$ in the same solvent, after individual sonication of the two components. Moderate heating maximized solubility of the polyaniline and resulted in the formation of a suspension of tiny particles in a dark-blue solution. In this way, mass ratios of $1: 1,2: 1$, and $5: 1$ $\mathrm{PANi} / \mathrm{CAHP}$ were prepared. In some cases, a mass of 17 or $65 \mathrm{mg}$ of camphor sulfonic acid (CSA, Sigma, St. Louis, MO) was also added to the solution before heating.

Thin films were prepared by placing $3 \mu \mathrm{L}$ of solution on the surface of a glassy carbon electrode with a diameter $0.5 \mathrm{~cm}$ and polished with diamond particles down to $1-\mu \mathrm{m}$ particle size. To aid solvent evaporation, the electrode was heated to $40^{\circ} \mathrm{C}$ up to $20 \mathrm{~min}$. In some of the experiments, solution was filtered through a porous glass frit, No. 0 , before application to the electrode surface

\section{UV-visible spectral studies}

UV-visible absorption spectra were measured on Shimadzu UV 2000 and Perkin-Elmer Lambda 19 spectrometers, with samples on microscope slides. The effects of acids and other dopants were studied by either immersing in solutions of the appropriate acid $\left(\mathrm{HCl}, \mathrm{H}_{2} \mathrm{SO}_{4}, \mathrm{HClO}_{4}, \mathrm{H}_{3} \mathrm{PO}_{4}\right)$ or exposing the slides to the vapor $\left(\mathrm{NH}_{3}, \mathrm{I}_{2}\right)$.

\section{Electrochemical measurements}

Electrochemical experiments were conducted in $1.0 \mathrm{M}$ hydrochloric acid solution or $0.5 \mathrm{M}$ sulfuric acid solution. The electrochemical cell also contained a platinum gauze auxiliary electrode and a saturated calomel electrode as reference.

Cyclic voltammetry experiments were carried out either with an EG\&G PAR 273 potentiostat controlled by M270 software or with a homemade analogue potentiostat. Solutions were not deaerated and experiments were carried out at $25 \pm 1^{\circ} \mathrm{C}$.

\section{RESULTS AND DISCUSSION}

\section{Film characteristics}

Films of the emeraldine base form of PANi blended with the four cellulose esters $\mathrm{CA}, \mathrm{CP}, \mathrm{CAB}$, and CAHP were prepared by solvent casting from NMP. With the first three derivatives, the films were blue, whereas that with CAHP was green. Using an optical microscope, the films showed the presence of fairly large particles. For PANi/CAHP, films were also prepared in formic acid, in which the PANi was much more soluble. In this case, no large particles were observed in the films.

It was shown that better quality films could be obtained by spin coating the films onto microscope slides or glassy carbon electrodes, with typical thicknesses in the range of 50-100 $\mathrm{nm}$. The uniformity and homogeneity of the particle distribution were similar 


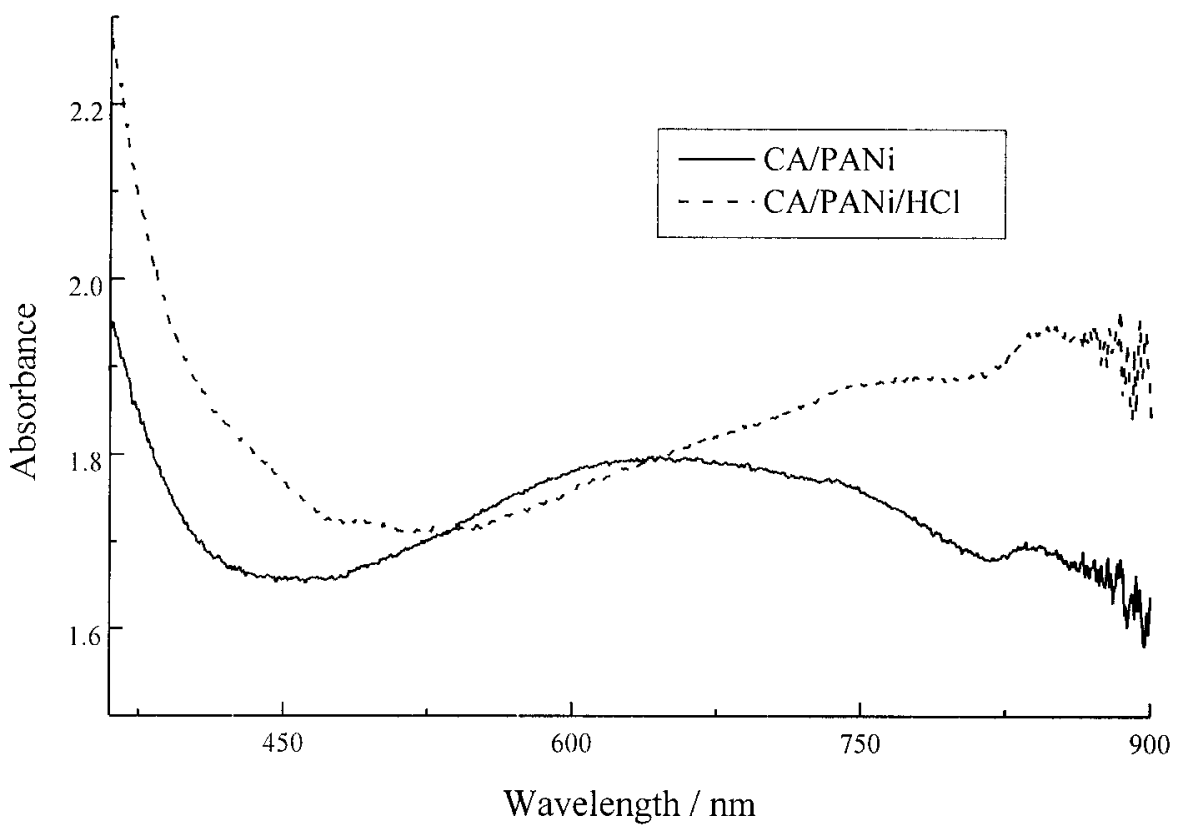

Figure 2 Absorption spectra of films of PANi/CA $(1: 1)$ untreated and doped with $\mathrm{HCl}$.

to that for thicker films, although the electrochemical response was more reproducible.

\section{Absorption spectra and the effect of doping}

UV-visible absorption spectra were measured of films of PANi/CA at various ratios of the two polymers. The spectrum of PANi/CA $(1: 1)$ film is shown in Figure 2(a). The undoped film showed transitions to the first excited state at $630 \mathrm{~nm}(1.97 \mathrm{eV})$ and to the second excited state at $350 \mathrm{~nm}(3.54 \mathrm{eV})$, in good agreement with literature reports. ${ }^{39}$ No significant effect of the ratio of the polymers, molecular weight, or polydispersity of the CA on the spectra was observed. In addition, no effect was observed on the absorption spectra on doping with iodine $\left(\mathrm{I}_{2}\right)$ or ammonia $\left(\mathrm{NH}_{3}\right)$ vapor. On doping with $\mathrm{HCl}$ solution, however, major differences were observed, with shifts of the absorptions to lower energies [Fig. 2(b)]. In agreement with previous reports, ${ }^{7,39}$ this is due to protonation of the emeraldine base form of PANi. Identical spectral changes were also observed on doping with solutions of $\mathrm{H}_{2} \mathrm{SO}_{4}, \mathrm{HClO}_{4}$, and $\mathrm{H}_{3} \mathrm{PO}_{4}$. UV-visible absorption spectra were also measured of films of PANi with CP and $\mathrm{CAB}$ alone and doped with $\mathrm{HCl}$. However, in spite of differences in the hydrophobicity of these polymers, ${ }^{40}$ the spectral and acid doping behavior were identical to that of the PANi/CA films.

In contrast, rather different behavior was observed with films prepared with CAHP. This shows the typical absorption due to the emeraldine salt, and no effect of $\mathrm{HCl}$ doping was observed (Fig. 3). The acidic hydrogen phthalate group appears to be acting as a proton donor in this case. Similar behavior was ob- served in films for this blend prepared from formic acid.

\section{Kinetic studies}

As previously reported for related systems, ${ }^{41,42}$ addition of acid to PANi/CA blends does not lead to immediate protonation, but instead leads to a slow spectral change corresponding to structural rearrangement of the PANi. Results obtained by following the spectral change at $630 \mathrm{~nm}$ for PANi/CA $(1: 1)$ on doping with $\mathrm{HCl}\left(10^{-2} \mathrm{M}\right)$ are shown in Figure 4 . The kinetic behavior was complex and could not be fitted by either first- or second-order kinetics. The doping showed a relatively short induction period (11 s) followed by a slower decrease in absorption. The total doping reaction was complete within $10 \mathrm{~min}$.

\section{Electrochemical behavior}

Although the films were prepared from emeraldine base, the electrochemistry is the same as that of polyaniline, because the films are immediately protonated when placed in sulfuric acid solution, and are converted to the reduced form as soon as the initial potential of $-0.2 \mathrm{~V}$ is applied. This is confirmed by the shape of the cyclic voltammograms (see below).

Cyclic voltammograms were recorded for mixtures of PANi with $\mathrm{CA}, \mathrm{CP}, \mathrm{CAB}$, and CAHP in NMP solvent. Figure 5 shows results obtained for the first three of these cellulose esters in $1.0 \mathrm{M} \mathrm{HCl}$. Compared with the voltammetric response of pure PANi, the oxidation and reduction peaks occur in the positions expected for polyaniline insulating-to-conducting 


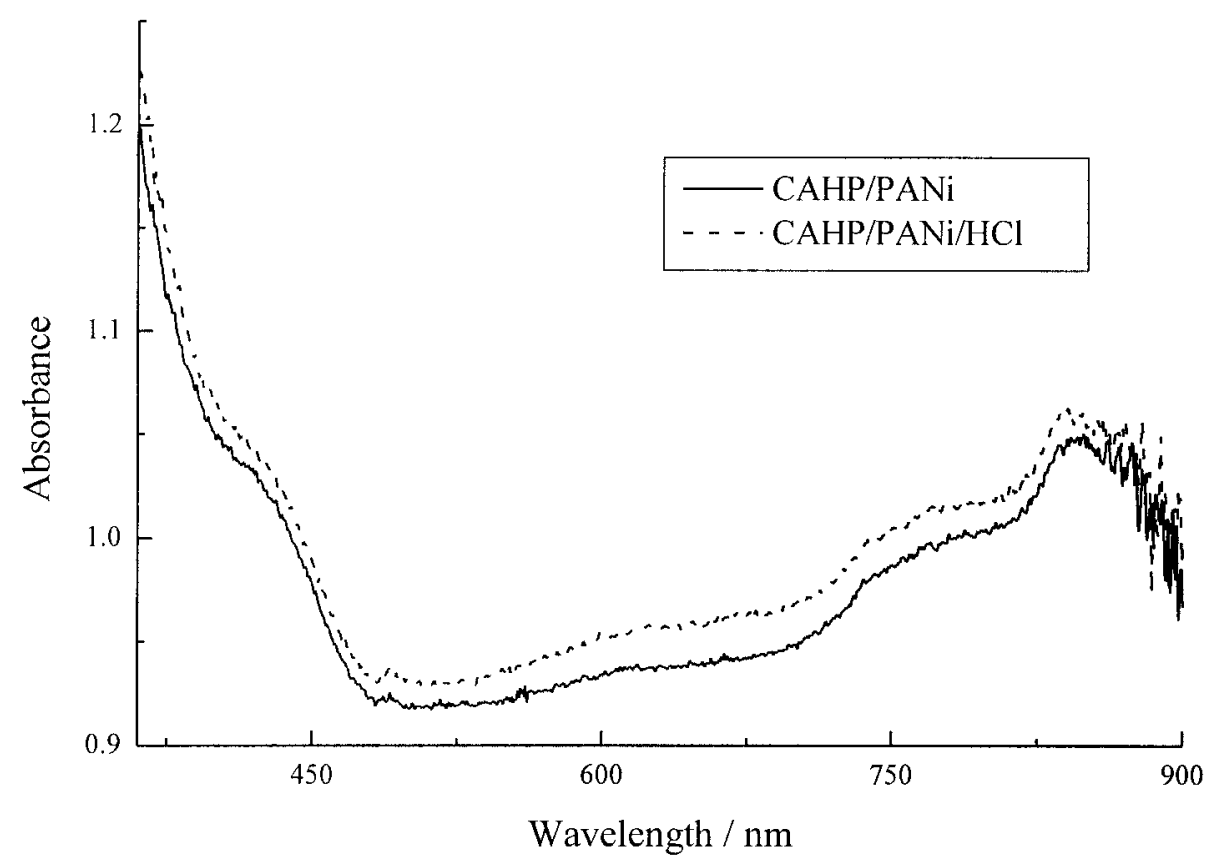

Figure 3 Absorption spectra of films of PANi/CAHP $(1: 1)$ untreated and doped with $\mathrm{HCl}$.

transitions, but they are poorly defined. Additionally, there is large hysteresis between the nonfaradic background currents in the scans in positive and negative directions, which can be attributed to charge separation, problems of conductivity within the polymer matrix, and diffusion of counter ions into the film. As the substituent ester groups attached to the pyranose ring increase in length from acetyl through propionyl to $n$-butyl (mixed with acetyl), the hydrophobic effects would be expected to increase. This would reduce the conductivity through the polymer matrix and increase charge separation, thence, the much increased hysteresis in the cyclic voltammograms noticed between $\mathrm{CP}$ and $\mathrm{CAB}$ matrices.

Films of PANi in a CAHP matrix, which is less hydrophobic, gave a much improved response. The PANi is partially protonated PANi because of proton transfer from the $-\mathrm{COOH}$ group in $\mathrm{CAHP}$, resulting in improved miscibility and easier electron transfer. This is clearly shown by the better definition of the oxidation and reduction peaks in the cyclic voltammogram of Figure 6 of a film prepared from a 1:1 mass

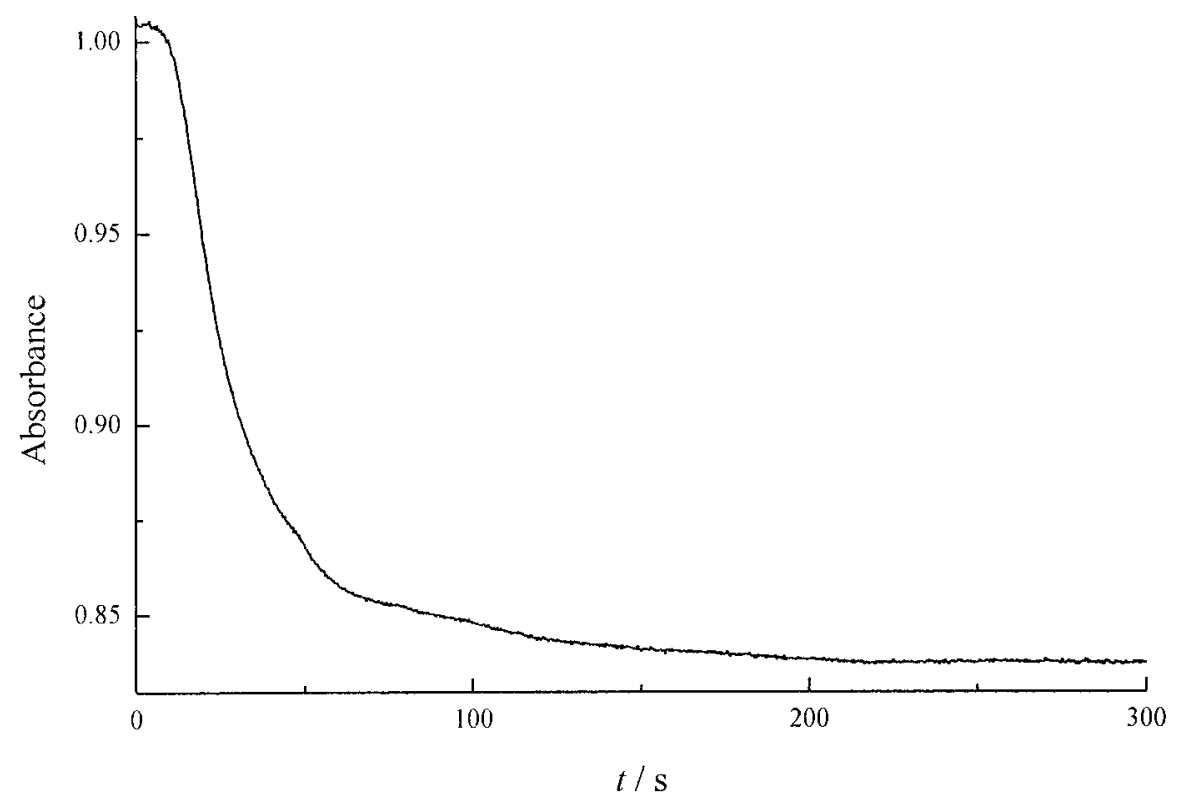

Figure 4 Kinetic studies of the reaction of the film PANi/CA $(1: 1)$ on doping with $\mathrm{HCl}\left(10^{-2} \mathrm{M}\right)$ observed at $630 \mathrm{~nm}$. 
(a)

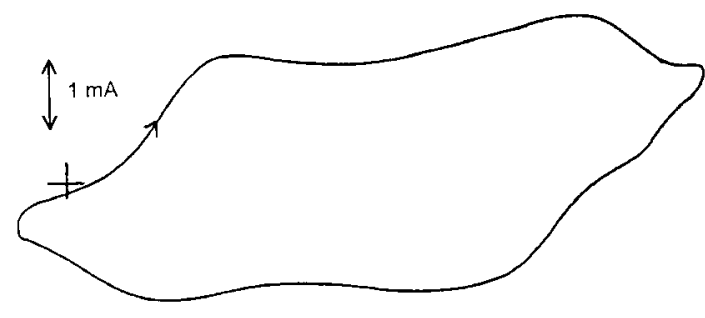

(b)

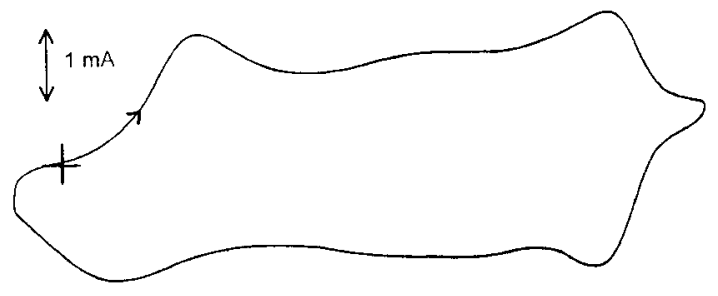

(c)

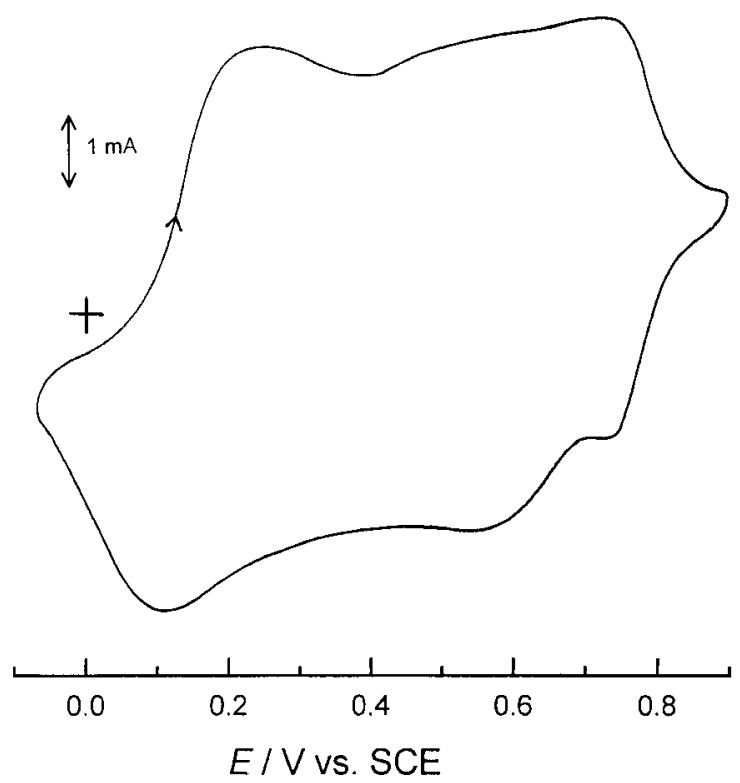

Figure 5 Cyclic voltammograms in $1.0 \mathrm{M} \mathrm{HCl}$ of films formed from $1: 1$ mass ratio of PANi with (a) CA, (b) CP, (c) CAB in NMP. Scan rate, $50 \mathrm{mV} \mathrm{s}^{-1}$.

ratio in $0.5 \mathrm{M} \mathrm{H}_{2} \mathrm{SO}_{4}$. The response in $1.0 \mathrm{M} \mathrm{HCl}$ was identical. This figure also demonstrates that the effect of filtering the solution on the position of the first anodic peak and on the value of the corresponding peak current is, in this case, essentially zero, given the predicted variations in thickness and uniformity of particle distribution between different films formed, estimated as $5 \%$.

If the ratio of PANi to CAHP is increased to $2: 1$ (i.e., more PANi for the same mass of CAHP), one would expect more and larger particles of PANi present in the film-forming solution, owing to solubil- ity limitations. Thus, differences between filtered and unfiltered solutions used to form the films should be more apparent. This is indeed the case as seen in Table I and is corroborated by the visual appearance of many particles in the unfiltered solution. Thus, a large percentage of PANi present is removed by filtering and this leads to a decrease of peak current to almost half. This is good evidence that particles of PANi may be necessary to furnish good conduction through the film. Given their size and that they are encapsulated in the CAHP matrix, an easier conducting path from the electrode substrate through to the solution arises.

It was found that formic acid is a better solvent for polyaniline than is NMP in the presence of CAHP and can be used to test the above hypothesis of the need for PANi particles. Figure 7 shows a typical cyclic voltammogram for a film of the blend formed at $1: 1$ mass ratio. It can be seen that the voltammetric peaks are less well defined than using NMP solvent, and the peak currents are significantly lower. The capacitive hysteresis is similar to that obtained from films formed from NMP solutions. Microscopic observation shows no visual evidence of particles in the $1: 1$ solution, and only a small amount of dispersed particles for $2: 1$ and $5: 1$ ratios. Table I shows how the peak current increases as the ratio of PANi to CAHP is increased, but not reaching the values mentioned for NMP solvent. These results corroborate those obtained from NMP solvent.

The influence of a dopant such as camphor sulfonic acid (CSA), added to increase the conductivity of $\mathrm{PANi}$ and a higher degree of protonation than with CAHP, is also given in Table I. For NMP films, there is essentially no alteration in the first anodic peak current, although some change in the voltammetric profile is evident. This is probably because the CSA reacts with the basic NMP rather than doping the polyani-

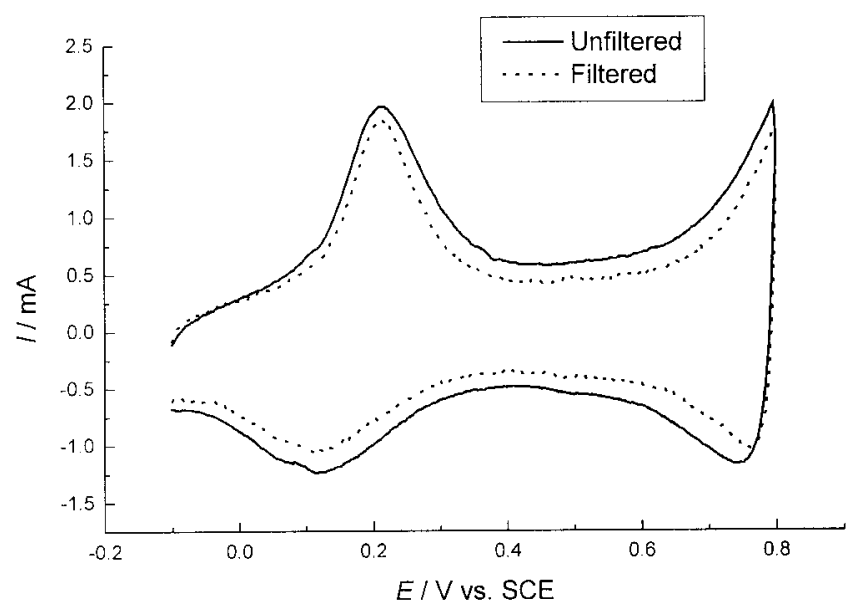

Figure 6 Cyclic voltammograms in $0.5 \mathrm{M} \mathrm{H}_{2} \mathrm{SO}_{4}$ of films formed from 1:1 mass ratio of PANi/CAHP in NMP solvent. Scan rate, $50 \mathrm{mV} \mathrm{s}^{-1}$. 
TABLE I

Effects of Solvent and Filtration on Position and Peak Current of First Anodic Peak of Films Formed from PANi and CAHP Studied by Cyclic Voltammetry, Scan Rate $50 \mathrm{mV} \mathrm{s}^{-1}$ (mass of CAHP constant at $17 \mathrm{mg} \mathrm{in} 5 \mathrm{~cm}^{3}$ )

\begin{tabular}{|c|c|c|c|c|c|}
\hline Solvent & $\begin{array}{c}\text { Ratio } \\
\text { PANi : CAHP }\end{array}$ & Comments & $E_{p, 1} / \mathrm{mV}$ & $I_{p, 1} / \mathrm{mA}$ & Visual appearance ${ }^{a}$ \\
\hline \multirow[t]{6}{*}{ NMP } & \multirow[t]{2}{*}{$1: 1$} & Unfiltered & 210 & 1.45 & Occasional clusters of tiny particles \\
\hline & & Filtered & 210 & 1.40 & No particles \\
\hline & \multirow[t]{2}{*}{$2: 1$} & Unfiltered & 250 & 1.60 & Lots of particles \\
\hline & & Filtered & 200 & 0.90 & No particles \\
\hline & \multirow[t]{2}{*}{$1: 1: 1(\mathrm{CSA})$} & Unfiltered & 205 & 0.42 & Particles in clusters \\
\hline & & Filtered & 210 & 0.25 & Cluster formations \\
\hline \multirow[t]{5}{*}{$\mathrm{HCOOH}$} & $1: 1$ & Unfiltered & 240 & 0.40 & No particles \\
\hline & $2: 1$ & Unfiltered & 250 & 0.40 & Dispersed particles \\
\hline & $5: 1$ & Unfiltered & 250 & 0.80 & Dispersed particles \\
\hline & $1: 1: 1$ (CSA) & Unfiltered & 220 & 0.60 & No particles \\
\hline & $5: 1: 5$ (CSA) & Unfiltered & 240 & 1.60 & Occasional particle \\
\hline
\end{tabular}

${ }^{\text {a }}$ Visual observation of films formed on microscope slides.

line. The influence of CSA in formic acid is rather different, because doping of PANi occurs, leading to increased miscibility, with very little particle formation, together with an increase in the low currents otherwise observed.

\section{CONCLUSION}

PANi films in a cellulose ester matrix can be readily prepared from NMP or formic acid solvents. The blends with the acetate hydrogen phthalate are of particular interest as the host is seen to protonate the PANi. It is shown that the films contain particles of undissolved PANi and that these are important for electrical conductivity as they bridge the film from the electrode side through to the electrolyte. In NMP solvent, the concentration of particles is greater; higher oxidation and reduction currents were observed and so NMP solvent is to be preferred. Additionally, CAHP/PANi films show potential as an acid/base

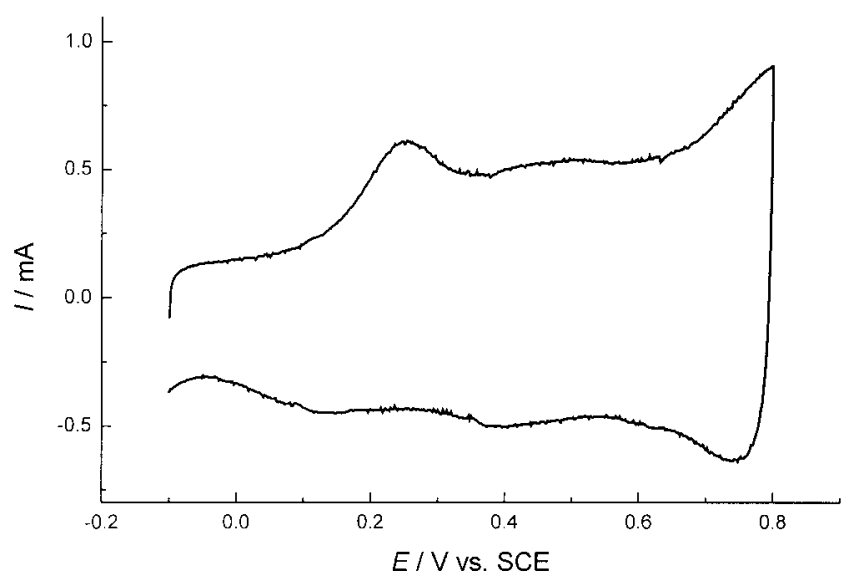

Figure 7 Cyclic voltammograms in $0.5 \mathrm{M} \mathrm{H}_{2} \mathrm{SO}_{4}$ of films formed from 1:1 mass ratio of $\mathrm{PANi} / \mathrm{CAHP}$ in $\mathrm{HCOOH}$ solvent. Scan rate, $50 \mathrm{mV} \mathrm{s}^{-1}$. sensor, due to the presence of the hydrogen phthalate group, which can protonate PANi.

We are grateful to Cláudia S. N. Fernandes for assistance in some of the experiments, and to the British Council/CRUP (project B-9/97), PRAXIS XXI (project 2/2.1/411/94), and the EPSRC (grant GR/M 40387) for financial assistance.

\section{References}

1. Acacer, L. (Ed.), Conducting Polymers, Special Applications; Dordrecht: Reidel, 1987.

2. Brédas, J. L.; Silbey, R. (Eds.), Conjugated Polymers: The Novel Science and Technology of Highly Conducting and Nonlinear Optically Active Materials; Dordrecht: Kluwer, 1991.

3. Salaneck, W. R.; Clark, D. T.; Samuelson, E. J. (Eds.), Science and Applications of Conducting Polymers; Bristol: Adam Hilger, 1991.

4. Prasad, P. N.; Mark, J. E.; Fai, T. J. (Eds.), Polymers and Other Advanced Materials. Emerging Technologies and Business Opportunities; London: Plenum, 1995.

5. Skotheim, T. (Ed.), Handbook of Conducting Polymers; New York: Marcel Dekker, 1997.

6. Petty, M. C.; Bryce, M. R.; Bloor, D. (Eds.). An Introduction to Molecular Electronics; London, Edward Arnold, 1995.

7. MacDiarmid, A. G.; Epstein, A. J. Faraday Disc Chem Soc 1989, $88,317$.

8. Syed, A. A.; Dinesan, M. K. Talanta 1991, 38, 815.

9. Wang, Y.; Rubner, M. F. Synth Met 1992, 47, 255.

10. de Surville, R.; Jpzefowicz, M.; Yu, L. T.; Perichon, J.; Buvet, R. Electrochim Acta 1968, 13, 1451.

11. Diaz, A. F.; Logan, J. A. J Electroanal Chem 1980, 111, 111.

12. Kabayashi, T.; Yoneyama, H.; Tamura, H. J Electroanal Chem 1984, 161, 419.

13. Yano, J.; Ogura, K.; Kitani, A.; Sasaki, K. Synth Met 1992, 52, 21.

14. Lamy, C.; Leger, J.-M.; Garnier, F. in Handbook of Organic Conducting Molecules and Polymers; Vol. 3, Nalwa, H. S., Ed.; Wiley: Chichester, 1997; Chapter 10.

15. Barker, P. S.; Di Bartolomeo, C.; Monkman, A. P.; Petty, M. C.; Pride, R. Sens Actuators, B 1995, 24/25, 451.

16. Kula, A. L.; Shirshov, Yu. M.; Piletsky, S. A. Sens Actuators, B 1996, 37, 135.

17. Fahlman, M.; Jasty, S.; Epstein, A. J. Synth Met 1997, 85, 1323.

18. Santos, J. R., Jr.; Mattoso, L. H. C.; Motheo, A. J. Electrochim Acta 1997, 43, 309. 
19. Huang, S.-C.; Ball, I. J.; Kaner, R. B. Macromolecules 1998, 31, 5456.

20. Gustafsson, G.; Cao, Y.; Treacy, G. M.; Klavetter, F.; Colaneri, N.; Heeger, A. J. Nature 1992, 357, 477.

21. Cao, Y.; Treacy, G. M.; Smith, P.; Heeger, A. J. Appl Phys Lett 1992, 60, 2711.

22. Mäkelä, T.; Sten, J.; Hujanen, A.; Isotalo, H. Synth Met 1999, 101, 707.

23. Cao, Y.; Smith, P.; Heeger, A. J. Synth Met 1992, 3, 91.

24. Pomfret, S. J.; Adams, P. N.; Comfort, N. P.; Monkman, A. P. Polymer 2000, 41, 2265.

25. Yang, C. Y.; Reghu, M.; Heeger, A. J.; Cao, Y. Synth Met 1996, 79, 27.

26. Subramanian, C. K.; Kaiser, A. B.; Gilberd, P. W.; Liu, C.-J. Wessling, B. Solid State Commun 1996, 97, 235.

27. Ghosh, M.; Barman, A.; De, S. K.; Chatterjee, S. Solid State Commun 1997, 103, 629.

28. Conn, C.; Booth, N.; Unsworth, J. Adv Mater 1995, 7, 790.

29. Lee, W.-J.; Kim, Y.-J. Kaang, S. Synth Met 2000, 113, 237.

30. Proñ, A.; Zagorska, M.; Nicolau, Y.; Genoud, F.; Nechtschein, M. Synth Met 1997, 84, 89.
31. Wolter, A.; Bañka, E.; Genoud, F.; Proñ, A.; Nechtschein, M. Synth Met 1997, 84, 753.

32. Planès, J.; Bańka, E.; Senis, R.; Proñ, A. Synth Met 1997, 84, 797.

33. das Neves, S.; DePaoli, M.-A. Synth Met 1998, 96, 49.

34. Niziol, J.; Laska, J. Synth Met 1999, 101, 720.

35. Cheguettine, Y.; Planès, J.; Banka, E. Synth Met 1999, 101, 787.

36. Bogan, R. T.; Kuo, C. M.; Brem, R. J. in Kirk-Otheimer Encyclopedia of Chemical Technology; Vol. 5, 3rd ed.; Mark, H. F.; Otheimer, D. F.; Overberger, C. G.; Seaborg, G. T., Eds.; New York: Wiley, 1979; pp 118-143.

37. MacDiarmid, A. G.; Chiang, J.-C.; Richter, A. F.; Epstein, A. J. Synth Met 1987, 18, 285.

38. Adams, P. N.; Laughlin, P. J.; Monkman, A. P.; Kenwright, A. M. Polymer 1996, 37, 3411.

39. Huang, W. S.; MacDiarmid, A. G. Polymer 1993, 34, 1833.

40. Valente, A. J. M.; Polishuk, A. Ya.; Lobo, V. M. M.; Burrows, H. D. Langmuir 2000, 16, 6475.

41. Fraoua, K.; Delamar, M.; Andrieux, C. P. Synth Met 1996, 78, 131.

42. Malinauskas, A.; Holze, R. Ber Bunsenges Phys Chem 1997, 101, 1851. 